\title{
Analysis on Problems and Strategies of Interactive Teaching Model in Higher Education
}

\author{
Lizhi Kong, Yubao Yan and Suolan Liu * \\ Changzhou University, Jiangsu, China, 213164 \\ lan-liu@163.com \\ * The corresponding author
}

Keywords: Interactive Teaching; Problems; Strategies; Analysis

\begin{abstract}
Interactive teaching is a kind of interaction and mutual influence between teachers and students, students and students in the classroom teaching. It will promote the psychological or behavioral changes of teachers and students. Interactive teaching can be divided into different types. From the point of interactive subjects, there are interaction between teachers and students, and interaction among students. From the interactive content, there are cognitive interaction, emotional interaction and behavioral interaction. Thoroughly understand the influence factors of interactive teaching will help teachers create an equal interactive environment, improve the quality of classroom interaction and promote the all-round development of students.
\end{abstract}

\section{The Background of Interactive Teaching}

Interaction is a concept introduced from social psychology to classroom teaching. It exists between objects and objects, people and people, or people and objects (environment). The teacher-student interaction regarded as a form of teaching model is started to be encouraged in the outline of the basic education curriculum reform (Trial) issued by the Ministry of education. In particular, teachers should actively interact with students and develop together in the process of teaching, so as to properly deal with the relationship between imparting knowledge and developing their abilities. Therefore, interactive teaching mode refers to the full play of initiative and enthusiasm between teachers and students in the course of teaching and efforts to create a harmonious and joyful interactive situation, which requires students to devote themselves to the classroom, communicate with teachers actively, and give teachers feedback in time to finish the task of teaching. It can be seen that in the interactive teaching method, teachers still play the leading role in guiding students' learning, but students are the main subject of learning. Interactive teaching mode is different from traditional mono infusing teaching method. It pays more attention to communication and dialogue in the process of teaching. In terms of teaching philosophy, all teaching designs in traditional teaching model are for the sake of scores and teaching is concerned with the results, instead of the teaching process itself. However, interactive teaching focuses more on the teaching process, which cares what has been learned or what has not been mastered by students. It emphasizes the interaction between students and students, the communication between teachers and students, and then finding out answers based on fully discussing and communication. In China, after more than a decade of advocacy and practice, interactive teaching has made great changes in classroom teaching, and has become an important evaluation standard for effective teaching. However, because of the educational background difference between Chinese and foreign countries, the popularization of interactive teaching mode has always been stayed in the beginning stage, and it has not been penetrated to classroom teaching in an all-round way.

\section{Problems in the Process of the Popularization of Interactive Teaching}

At present, the interactive teaching is not fully perfect. It is also faced with a series of practical problems in the aspects of teachers and students' ideas, teaching resources, teaching assessment and 
management mode. As supporters of interactive teaching reform, authors in this paper have a deep understanding of practical teaching about this mode.

Issues on the Theoretical Basis. The theory of interactive teaching emphasizes students as the center, which not only requires the students to transform themselves from passive recipients into the subjects of information processing and the active constructors of knowledge significance, but also needs teachers to transform themselves from knowledge impartosr and instilators into the helpers and facilitators of guiding students to study initiatively. However, in practical teaching, the teacher often lets the students study after some simple guidance. Therefore, it is difficult for most students who are not adapt to the teaching mode to know what should be mastered, which results in many problems. It should take a lot of time to correct the misunderstandings. This often causes the students to be in a heavy cognitive load state, and easily makes students' boredom and increases the work for teachers to repeat teaching.

Problems of Knowledge Structure and Systematicness. According to the complexity and variability of knowledge application, it can be divided into well structured knowledge and poorly structured knowledge. Knowledge in well structured fields usually means having fixed answers, such as the basic concepts involved in learning. Knowledge in poorly structured fields arised from applying knowledge into the well structured domain aims to resolve specific problems, which generally refers to the application of some concepts. Obviously, for the well structured knowledge, students should be skilled through extensive practice and repetition. We should not blindly adopt the information, decision-making, planning, implementation, inspection and evaluation in interactive teaching model. Otherwise, we can only get half the results with twice the effort.

On the other hand, compared with the traditional teaching method, in the interactive teaching students are regarded as the main body to organize the teaching of knowledge points. Therefore, it is usually difficult for students to systematically grasp the knowledge. It takes more time to wholly clarify knowledge and skills than before.

Contradiction Between Teaching Methods and Curriculum Requirements. Teaching methods are carried out to achieve the purpose of teaching, realize the content of teaching and use some teaching measures. It is a whole set of teaching principles based on the interaction between teachers and students. Accordingly, the superiority of teaching methods is the key to achieving teaching objectives and completing teaching tasks. Therefore, it is not appropriate to implement interactive teaching for all subjects in the current state. How to select suitable subjects for interactive teaching is a key issue for teaching administrators.

Problems of Teaching Assessment. The evaluation of teaching effectiveness by traditional teaching mode is mainly based on the final examination and sometimes considering the performance at ordinary time. Obviously, the traditional evaluation method can not be used to test and reflect students' performance and learning activities in interactive teaching. Interactive teaching assessment should include self assessment, group mutual evaluation, teacher evaluation and reply. Therefore, there are many contents in assessment, which makes students hard to deal with the assessment and causes much complain.

\section{Several Strategies for Interactive Teaching}

The purpose of interactive teaching is to resume the dominant status of students and help students become introspectors and actors in the process of solving problems. So, it is not a specific teaching behavior, or the only teaching form in the classroom. It should be a kind of teaching method coexisting with lecture-style teaching, exploring teaching or dialogue teaching. It should include cognitive components, emotional components and behavioral components. In this regard, knowing the existing problems and doing some further reflection can help to clear the future development of interactive teaching mode.

Strengthening the Learning of Guiding Ideas and Accurately Grasp the Interaction Roles. In order to make the interactive teaching model really popularized, it is necessary for the educators to strengthen the promotion of the interactive teaching ideas. Encourage and motivate teachers and 
students to try their best. Especially for some rigid and conservative teachers, regular training is very necessary.

In fact, interactive teaching is a process of two subjects and two-way communication. In this process, the relationship between teachers and students is no longer the model of the elders and the juniors in the traditional teaching. In the teaching activities, teachers should play leading roles, pay full attention to students, and truly return all the rights of the classroom to students. So that students can discover deficiencies in the process through autonomous learning, and give feedback to teachers. In interactive teaching mode, teachers should firstly clear their position. They still play leading roles, but they are no longer the inculcators of knowledge as in traditional education mode. Now, the leading role of teachers is mainly reflected in the design and application of teaching methods. Interactive teaching puts forward high requirements for teachers' quality and classroom management skills. The key of successful teaching is to fully mobilize the multidirectional interaction in the classroom.

Emphasize the Study of Teaching Methods. The foundation of interactive teaching mode is constructivism psychology. In the whole teaching process, teachers are only the guides of knowledge construction, and students are the rebuilders of knowledge. To make the students feel more profound in the reconstruction of knowledge, teachers should pay attention to the research of teaching methods. Teachers should study the advantages from traditional teaching models and attach importance to knowledge's certainty and universality, and pay attention to its analysis and abstraction at the same time. This will enable students to grasp a large amount of systematic scientific knowledge in a short time and avoid many unnecessary twists and difficulties in the process of cognition.

Pay Attention to the Individual Development of Students. Interactive teaching emphasizes the integrated development of students' personality. This actually includes two-level meanings. Firstly, to make students get comprehensive development means all aspects of learning are involved and balanced, not only focuses on one aspect; Secondly, this development is not carried out in a balanced manner in all aspects, but requires the students to side in certain aspects according to their own special specialities and interests, so as to better reflect and develop their own specialties and hobbies. As is known to all, the basic task of teaching is to promote the all-round development of students' personality, which requires teachers to give their attention to students from multiple perspectives, pay attention to their personality characteristics, and give different students different opportunities in classroom, so as to truly teach students in accordance with their aptitude.

\section{Conclusion}

Interactive teaching is an open, interactive and diversified teaching form, which has many differences from traditional presupposition teaching. From the content and design of teaching, the traditional teaching is concerned with the precise design of fixed content, but the content of interactive teaching has a certain randomness and flexibility. The teacher provides a rough framework for teaching design under the condition of fully presupposition of all kinds of assumptions. In terms of the implementation of teaching and the relationship between teachers and students in the classroom, the traditional teaching shows as the established design of teachers and the passive acceptance of the students. However, the interactive teaching is a new relationship between teachers and students, students and students in teaching interaction, cooperation and mutual exploration under the guidance of teachers. It stands for a new type of equality and cooperation between teachers and students.

\section{Acknowledgements}

This work is supported by the project of Changzhou University (No.2015XSJ11 and No.CDGZ2016002) . 


\section{References}

[1] O Nadezhda, V Evgeny. Interactive teaching methods in contemporary higher education [J]. Pacific science review, 2014(16): 75-80.

[2] V Lukashevich, I Shegelman, Y Sukhanov. Introduction of Interactive Teaching Methods into the Disciplines of Forest Specialities: A Case of Petrozavodsk State University [J]. Social and Behavioral Sciences, 2015: 119-127

[3] M Capel, A Tomeu, A Salguero. Teaching concurrent and parallel programming by patterns: An interactive ICT approach [J]. Journal of Parallel and Distributed Computing, 2017,105: 42-52.

[4] A Ishkov, M Leontiev. Interactive Teaching Methods in Small Groups of Bachelors and Construction Specialists [J]. Procedia Engineering, 2015,117: 142-147.

[5] D Mavrikios, K Georgoulias, G Chryssolouris. The Teaching Factory Paradigm: Developments and Outlook [J]. Procedia Manufacturing. 2018, 23:1-8.

[6] J Linhart. A field guide for teaching evolution in the social sciences [J]. Evolution and Human Behavior, 2018,39 (3): 257-268

[7] J Bowen. Teaching naked: How moving technology out of your college classroom will improve student learning [J]. San Francisco, CA: Jossey-Bass, 2012.

[8] H Qin, Z Zhou, W Hu. The influential factors of classroom interaction and teaching revelation $[\mathrm{J}]$. Theory and practice of education, 2008,28:42-45

[9] Z Zhang. The dilemma and resolution of teaching based on teacher-student interaction [J]. China academic journal, 2015,6:44-52.

[10] Y Zheng, Y Wu. Approaches for improving professors' teaching arts in top universities [J]. Journal of UESTC (Social sciences edition), 2010(12): 107-109.

[11] E Karen, B Etzkorn. Learning to teach online: Measuring the influence of faculty development training on teaching effectiveness through a TPACK lens [J]. The Internet and Higher Education. 2018, 38: 28-35

[12] X Jia, W Hu, F Cai. The influence of teaching methods on creative problem finding [J]. Thinking Skills and Creativity, 2017, 24: 86-94

[13] G Mason, T Shuman. Comparing the effectiveness of an inverted classroom to a traditional classroom in an upper-division engineering course[J]. Education, 2013,56(4):430-436

[14] Michille. University teachers' innovative teaching behavior and the relationship between the innovative ability of college students Investigate [J]. Journal of teaching research, 2013, 15-18.

[15] S Sharma, A Ali, R Takhelmayum, R Nair. Co-teaching: Exploring an Alternative for Integrated Curriculum[J]. Journal of the National Medical Association, 2017,109(2): 93-97. 